\title{
Language, Social Media and Political Identity (Re)presentation: A New Theoretical Framework for the Analysis of Social Media Political Discourse
}

\author{
Farhat Sajjad ${ }^{1}$, Mehwish Malghnai ${ }^{2} \&$ Durdana Khosa $^{2}$ \\ ${ }^{1}$ National University of Modern Languages, H/9 Islamabad, Pakistan \\ ${ }^{2}$ SBK Women's University, Quetta, Balochistan, Pakistan \\ Correspondence: Farhat Sajjad, National University of Modern Languages, H/9 Islamabad, Pakistan. E-mail: \\ Farhat092@gmail.com
}

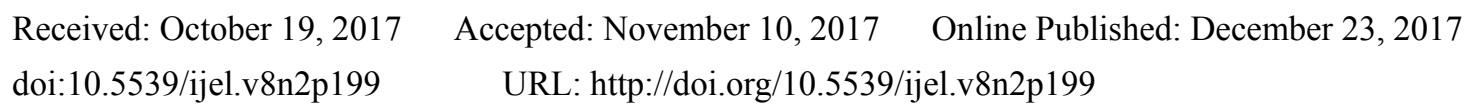

\begin{abstract}
As language is central to all social processes and practices, so it is considered as the most effective tool for (re)shaping and (re)constructing the social realities and political identities as they are negotiated, (re)constructed and thus projected in the broader social and cultural contexts. Since the advent of new media technologies, particularly social media, the forms and modes of political identity construction and (re)presentations are also transformed. As debated earlier that language enables its users, specifically political actors, to exhibit the political ideologies and identities effectively, so the political actors frequently exploit these platforms to achieve their pre-defined political agendas. Within the same context the political rhetoric, specifically the ones that is generated and exhibited on social media network sites, offers a new visibility for the researchers to explore and predict how ideologies and perceptions can be achieved, advocated, altered and rebuilt through discursive discourse strategies on these networking sites. Providing the power of social media for political participation, political engagement and political activism, there is a need to design such framework that can offer a different lens for the analysis of critical yet sensitive issue of political identity (re)presentation beyond the textual level. To address the above debated issue a new theoretical framework is presented in this paper that enables to analyse the text with special reference to the context in which the political identities are negotiated, (re)constructed and (re)presented. This framework is designed by collaborating the approaches of CDA, Political Identity theory, Social Media theory and Political Discourse theory that enables to explore the interrelationship between the "language in use" and the context in which it is created and consumed.
\end{abstract}

Keywords: language, political identity, (re)presentation, social media, CDA

\section{Introduction}

The theoretical framework is one of the most important element for research based studies as it provides the foundation on which the whole scholarship is built with special reference to theoretical concepts, analytical frameworks etc. (Sekaran \& Bougie, 2010) In the current study theory triangulation is offered to get a better understanding about the text from analysis perspective. The term "theory triangulation" directly refers to "use of multiple perspectives to handle a single text for the sake of interpretation" (Denzin, 1970, p. 279). Denzin (1970), elaborated theory triangulation as the use of multiple theories in the same research study for the purpose of supporting or refuting research findings since multiple theories provide different lenses to the researcher to approach data. Banik (1993), suggested that related or competing theories can be used in formulating a hypothesis for any specific scholarship. To get a clearer understanding of the concept of theory triangulation it is important to note that triangulation does not require the use of three theories, three reference points or three options. In fact, it means just more than one (Denzin \& Lincoln, 1994; Tashakkori \& Teddlie, 2003). According to Mathison (1988), theory triangulation provides coverage of an accurate representation of a particular reality by interpreting data from multiple perspectives. It means that theoretical triangulation enables a researcher to validate the research analysis and research findings from a better perspective. The trend of theoretical triangulation is becoming common in social sciences where the researchers get an opportunity to reach the data through multiple lenses and thus the process of result interpretation becomes easier. By keeping in view the same 
facts the current study has focus upon the significance of theoretical triangulation by proposing a new model for the analysis of social media political discourse. Political discourse is an interesting type of text that reflects the ideologies and identities of discourse makers and the same text becomes more crisp and significant when it is produced and consumed by the e-users. By keeping in mind the same quality of digital political discourse the current model is proposed in this research paper.

\section{Literature Review}

\subsection{Political Discourse Analysis}

Political discourse is basically a field of discourse analysis which primarliy focuses upon the discourse practices produced in specific political forums or political spheres such as parlimentary debates, legislative processes, hearings etc. (Johnson \& Johnson, 2000) So it can be elaborated as a field of disourse analysis which stresses upon the political discursive events in order to reveal the hidden ideologies and massive agendas of political actors. According to Van Dijk (1993, 1995, 1998c \& 2006) political discourse does not refer only to the discoruse of politicians who perform certain political actions but also tothat of all those stake holders who directly or indirectly perform their roles in discursive political events. Further, political discourse demonstrates political activities of electors, pressure groups, media, political parties, political workers, power groups, pressure groups etc. The discourse primarily occurs through written and spoken text (Van Dijk, 1998c). A very significant or common/familiar category of political discourse consists of speeches within the parliment house and they are delivered by political leaders (Van Dijk, 1998c). Other forms may include various formal situations such as political campaigns, conferences, legislative processes, interviews and public meetings. Some political leaders and pressure groups display their ideas through magazines, books, newspapers etc and many other means.

Political discourse analysis of Van Dijk (1998c) deals with the power relations, it focuses upon how political power is gained, contested and maintained. So the Political Discourse Analysis adopts a critical perspective for the interpretation of political discourse (Van Dijk, 1998c; Wodak, 2009) at various levels. According to Van Dijk's (1998c) perspective, political discourse analysis is about the study of identity (re)presentation, ideology (re)construction and manifestation, power abuse, power dominance, power exercise, power manipulation etc. (Chilton, 2004; Van Dijk, 1998c; Wodak, 2009) It was also argued that political discourse analysis looks at how power is resisted with reference to power resistance in the specific context of discursive discourse practices. It enables political actors to project their identities through discourse (Van Dijk, 1993, 1998c; Werth, 1999; Fairclough, 1995, 2000, 2002; Wodak \& Meyer, 2001; Wodak, 2000, 2009). Van Dijk (1998c) treats political discourse as a set of discursive practices which critically involve all political actors ranging from professional politicians to political workers, political activists, pressure groups and oppressed groups, etc. Political discourse analysis appears as an interpretative practice and approach which tries to investigate the particular genres within specific political context.

According to Fairclough (1995) and Van Dijk (1998c), political context offers a great opportunity to its actors to create such discursive discourse practices in local and international institutions whi ch are quiet challenging for the discourse analysts from interpretative point of view. Furthermore political discourse can not be considered as an exclusive category of analysis because of its discursive nature and the influence of many other stakeholders who covertly or in few cases overtly shape the political discourse (Chilton \& Schäffner, 2002; Van Dijk, 1993; 1998c; Wodak \& Meyer, 2001; Wodak, 2009).

Van Dijk (1998c), proposed the following categories for the analysis of political discourse.

\subsubsection{The Domain of Politics}

Van Dijk proposed that political discourse should not be taken just as a process involving political actors, political settings, or political context. There are a number of other compulsory elements which form political discourse, such as, political systems like ideology, power, inequalities etc. (Van Dijk, 1998c) Some important categories of political text and context, as per Van Djik (1998), are provided in Figure 9 below. 


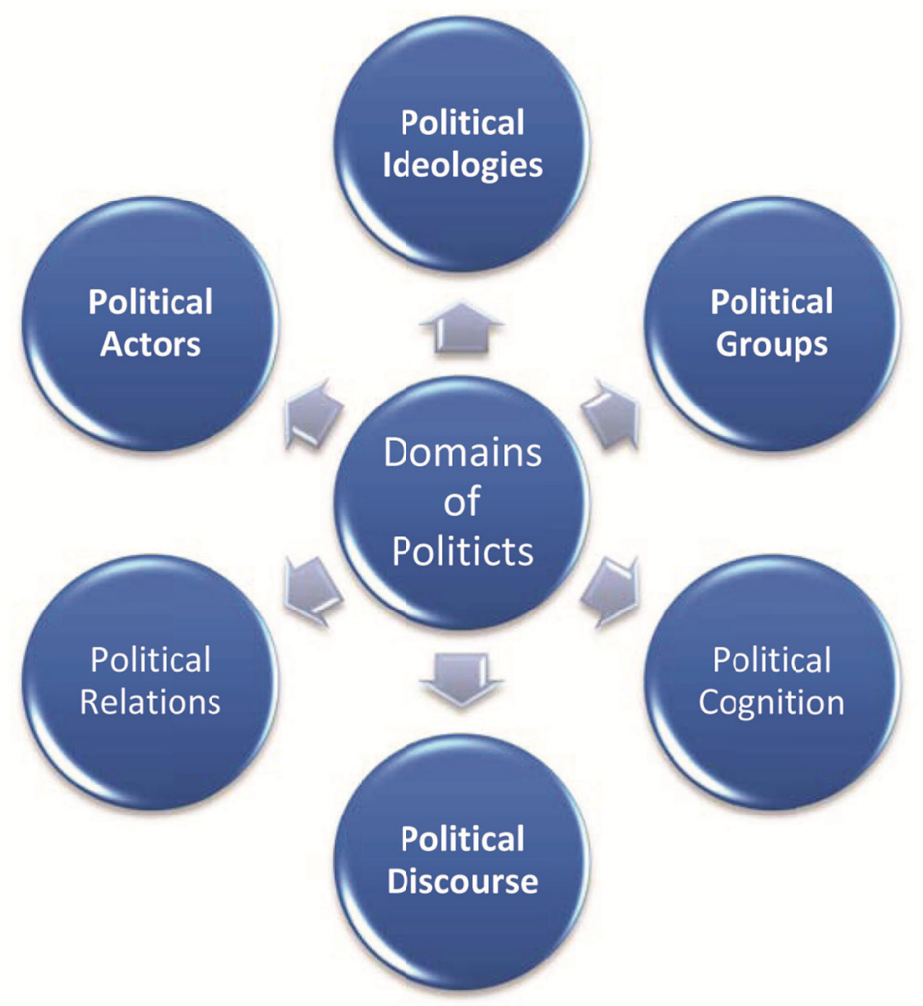

Figure 1. Categories of political discourse analysis by Van Dijk (1998)

\subsubsection{Political Ideologies}

Political ideology is an important feature of political discourse. It is defined as a set of socio-cognitive value systems which are adopted by the political actors for the demonstration of shared-representation of political groups and their members. (Van Dijk, 1998c; Chilton \& Schäffner, 2002; Wodak, 2009)

\subsubsection{Political Groups}

Central to political discourse are the various political groups who collectively constitute a political discourse. Political groups define the structural patterns of a specific political discourse because discourse is a discursive entity and it is shaped by the group members (van Dijk, 1996, 1988c ; Janks, 2006).

\subsubsection{Political Actors}

All those people who directly or indirectly "participate or engage in politics" are termed as political actors, they are not just professional political leaders or elected politicians rather all those people who participate in political discourse are called political actors (Van Dijk, 1998c; Wodak \& Meyer, 2001; Wodak, 2009).

\subsubsection{Political Relations}

The political relations are all those structural units which provide profound connections between political actors within a political system. Interestingly political relations define the successful achievement or attainment of political objectives for a certain political groups i.e. to what extent the political actors represent their political identities and ideologies to other political groups within a particular political system (Van Dijk, 1998c). The notion of political relation can be illustrated by how does state relate it to its citizens or how does an elected politicians behave with his followers or supporters etc.

\subsubsection{Political Discourse}

Political discourse refers to doing politics, means the different ways in which political actors perform political actions. Political discourse is discussed as an inclusive category because it counts upon a number of significant features from construction and representation point of view. In addition to delivering parliamentary speeches and debates, passing certain laws, propagandas, electoral campaigns etc. there are a number of institutional forms of text and talk including various genres such as political media talk shows, interviews etc. (Van Dijk, 1998c; Cap, 2006; Sheyholislami, 2001) 


\subsubsection{Political Cognition}

One of the most comprehensive categories of political discourse is labelled as "political cognition", which refers to the ways through which the discourse practices are locally created, generated, applied, interpreted and evaluated under set standards of a particular social and political system.

The current study has also focused upon the theoretical perspective as debated earlier.

\subsection{Socio-Cognitive Model of Van Dijk, A CDA Approach}

The first and foremost principle of critical discourse analysis is the study of all discursive practices. In other words the discursive practices define the ways through which the text is created, distributed and thus interpreted as a form of social practice (Fairclough, 1995, p. 27). These discrsive practices can never stand in isolation as a need of social and cultural factors always exist there. According to the theorists of CDA the main objective of CDA practioners is to highlight the linguistic-discursive aspects of social and cultural phenemenon which are embedded in every discourse practice (Fairclough, 1995; Van Dijk, 1998a, 1998c; Wodak \& Meyer, 2001).

CDA appears as "critical" because it seeks to reveal the role of power in the physical world of reality, it does not go for ambigious conceptual or methodological approach rather it tries to analyze the facts as they exist in the social world. It contributes to social change and it makes the communication process comprehendable from a critical perspective i.e., how discourse creates, sustains and thus projects the ideologies and identities (Van Dijk , 1989, 19993, 1998a, 1998c \& 2006; Wodak \& Meyer, 2001). Same agenda is adopted in this particular study as here the focus is on how political actors can (re)construct and (re)present political identities on Social Media. Van Dijk (1998) believed that to analyse media discourse it is essential to condcut structural and textual analysis alongwith reception i.e. how discourse is received and perceived. By "structural analysis" he meant not merely structures like grammatical categories or phonological properties rather a detailed analysis of high level properties like coherence, overall themes, rhetorical dimensions and overall topics should also be examined. It was believed that discourse is not only a textual or dialogic structure rather it is a communicative event that has a social context involving participants (Van Dijk, 1988, p. 2). It was also postulated that discourse analysis is done at micro and macro levels, at microstructure level, semantic categories, lexical and rhetorical aspects like quotations, direct/indirect speech etc. of discourse are taken into account. While at macro level contextual elements are analyzed given the fact that context mediates between society and soico-cultural background. Moreover it was argumented by Van Dijk that "discourse analysis is basically ideology analysis", "ideologies are typically, though not exclusively, expressed and reproduced in discourse and communication, including non-verbal semiotic messages, such as pictures, photographs and movies" (Van Dijk, 1995, p. 17). In this sense, for Van Dijk ideologies are socially constructed and thus linguistically represented and vice versa. Moreover ideologies portray the personal cognition of a group or individual and they are also termed as the reflection of shared attitudes. Ideologies project attitudes, beliefs, norms, etc that form the identity of a certain individual, so it is rightly stated Ideological representation are often articulated along Us versus Them dimensions, in which speakers of one group will generally tend to present themselves or their own group in positive terms, and other groups in negative terms (Van Dijk, 1998, p. 22).

Analysing and making explicit this contrastive aspect of Us versus Them remained central to a number of Van Dijk's research scholarships (1988, 1991, 1993, 1995, 1996, 1998a \& 1998b). The very nature and thoeretical stance of Van Dijk's model provided solid foundation for the cuurent study as the researcher has developed that model which primarliy fouces upon ideological square to understand the notion of "political identity (re)construction and (re)presentation".

\subsection{Social Identity Theory}

Social identity theory was developed by Tajfel \& Turner $(1979,1981)$, the theory was considered as a way to explain the intergroup behaviours. The theory emphasized upon psychological motivation that makes a group member to join/affiliate or renounce an existing membership. According to Turner, Penelope, Alexander, \& Craig (1994), the primary objective of social identity theory is to highlight the particualr labels which an individual or a group selects or gains from society to represent certain norms, values etc. moreover social identity enables to project the societal entities that handle the process of social categorization and social identification. Moreover social identity theory revolves around the psychological framework of identity markers and takes it at individual level as seen in the work of Erikson (1994) who postulated identity as "who we are as person, individual or group". Identity theory represents the notion of distinguishing between "our and other's group", moreover it was too proposed that the motive of social identity theory is "to differentiate their own groups positively from others to achieve a positive social identity" (p. 42) and thus appeared as a fluid entity. According to Huddy (2001), there are a number of off-shoots of social-identity theory on the basis of extensive research work carried by 
researchers in multiple ways and domains. Such as political psychologist remained much interested in knowing how groups are formed and how individuals associate themselves with certain political groups, societies etc. and what are common traits for consideration while deciding about group affiliations. So on the basis of such queries and interests the researcher has used "political identity" as one of the main theoretical constructs in the current study.

Political identity refers to the identification of individuals on the basis of political affiliations, i.e. individuals and groups associate themselves with certain political groups and thus they adopt the attributes of the political party to which they belong. Political identity develops certain biased approaches among the individuals and groups which thus lead them towards prejudice, monopoly; hegemony etc. Meister (2001) elaborated that political identity represents the role of consciousness and the political affiliation. It means there is a significant role of consciousness in developing political identity because while deciding about joining specific political group individuals rely upon their personal cognition, so it can be stated that political identity undergoes a critical process of development. (Meister, 2001) A lot of research work was conducted to analyze the nature of political identity with a specific focus upon the identification of all those markers which depict a close association between political identity and ideological perceptual ability of individuals. (Abrams, Political distinctiveness: An identity optimising approach., 2006) Reid Deaux (1986) analysed the social nature of political identities and labelled them as conservative, liberal, radical and socialists etc., it was also figured out that political identities are collective in nature and it is more highlighted as compared to other types of identities. According to Smucker (2011), politics is based on identity with a group and there can be no politics without identity with a group. Political identity is defined as an identification with a main political party or the adoption of an ideological moniker for self-descrption. (Abrams, Political distinctiveness: An identity optimising approach., 2006; Duck, Hogg, \& Terry, 1995) Within similar connotation Deaux, Reid, Mizrahi, \& Ethier (1995) proposed the social nature of the political identity. It is conservative, environmentalist, liberal, pacifist, radical, and socialist (cited in Huddy, 2001), it was also postulated that premise of social identity theory is efficiently applicable to religious, political and ethnic identity as these identities are more collective in nature than the other individual prospects of identity (p. 286).

The current study also revolved around multiple modes of "political identity (re)presentation" as it remains and appears fluid in multiple discursive discourse events.

\subsection{Clusivity Theory}

Clusivity refers to the different strategies of inclusion and exclusion that are linguistically coded in discourse. (Wieczorek, 2013) Clusivity primarily encompasses and investigates the occurrences of association and dissociation in the discourse practices which reflect the notion of "positive self-representation" and "negative other-representation". To proceed on with the discussion it is inevitable to elaborate "Inclusion and Exclusion" in broader societal and political context. Identifying oneself with a particular individual/group develops a specific sense of belongingness that primarily affects the perception of individual about certain norms, actions, behaviours, ideology etc. (Wieczorek, 2013)

As compared to inclusion, exclusion appears very different because it can be manifested in multiple forms such as physical, communicative and sometimes purely cognitive. (Abrams, Hogg, \& Marques, 2004) Exclusions are primarily formulated on the basis of geographical, religious, ethnic and ideological discrepancies between groups and individuals. (Abrams, Hogg, \& Marques, 2004; Abrams, 2006; Wieczorek, 2013) Within similar connotation Abrams, Hogg, \& Marques (2004) defined different levels of exclusions (a) societal exclusion, where chosen individuals or groups of individuals are consensually excluded from a society, (b) institutional exclusion, where institutions select particular groups to determine norms for both group association and dissociation practices, (c) intergroup exclusion, where groups establish clear demarcation lines to enhance their distinctiveness from other groups, and (d) intragroup exclusion, where groups establish sets of norms by means of which members can define themselves as fully legitimate members (p. 10).

Political actors mostly act coercively through linguistic choices for different objectives such as, for setting agendas, selecting topics, positioning oneself and others in particular relationships etc. (Esses, Dovidio, Jackson, \& Armstrong, 2011)

\subsection{Social Media Theory}

According to Zappavigna (2012) Social Media refers to digital sources of communication that enables users to create and disseminate information in very fast way. It is appropriate to say that social media has changed the face of communication reality in a dramatic way (Boyd \& Ellison, 2011), the utility of social media is emergent in terms of usage and effect. As mentioned earlier that it is used in multiple ways similarly, it has different forms 
and modes such as Facebook, Twitter (microblogging sites), LinkedIn, Orkut, My Space, Yahoo Messenger etc. are exclusively used for communication purposes (Aronson, 2012). Within same context, the type of discourse that appears on social media has emergent forms, such as, it is utilized for personal interactions, socialisation, academic information and learning, political communication and ideology demonstration, advertisement, marketing etc.

As language is central to politics, so the political communication that is done on social media primarily revolves around agenda -setting techniques. To achieve political objectives the political actors manipulate language accordingly, so to understand the hidden ideologies of politicians it is important to scrutinize the linguistic choices as they form the very nature of discourse. In this particular study political discourse that is generated on social media is examined to understand how political actors (re) construct and (re)present their political identities through linguistic choices. For this particular purpose the text along with context must be deeply investigated.

\section{Research Methods}

For the current study the researcher has taken the following constructs to strengthen the theoretical framework. Rather the researcher has used theoretical triangulation as a method of this research study. Researcher has combined the key constructs of five theories and put them together in theoretical triangulation to conduct a deep analysis of social media political discourse. From political discourse analysis theory the researcher has taken into account the constructs of political discourse, political ideology and political groups. Since the study is heavily relying upon the political text, so Political Discourse Analysis theory can facilitate the analytical process. The theory states how political text helps specific group of people termed as political actors to initiate, create and project political beliefs and political identities as these identities are embedded in political ideologies.

There are many types of triangulations as discussed here.

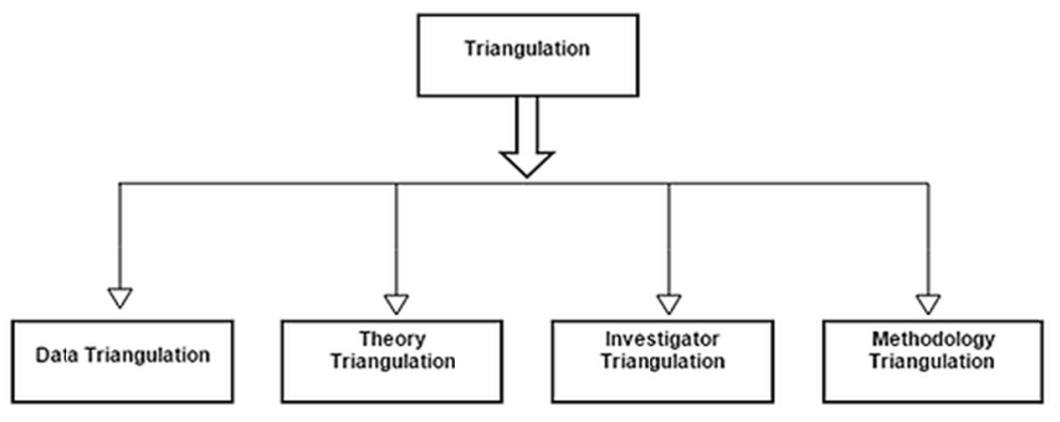

Figure 2. Types of triangulation (Denzin, 1994)

Data triangulation means collection of data from multiple sources as it facilitates the validation process, according to Denzin (1994) data triangulation is done from three perspectives; i.e. time, space and person. (Begley, 1996) While theory triangulation can be defined as the use of multiple theories in a single inquiry from the perspective of supporting or rebutting research findings, it helps researchers to investigate an issue through multiple lenses (Denzin, 1970 \& 1994). It was also debated that related or competing theories can facilitate in offering a broader and deeper understanding of the research issues (Banik, 1993). Investigator triangulation is the use of more than two researchers in any particular study (Denzin, 1970). It can be explained in terms of using multiple observers, interviewers, analysts for authentic result (Thurmond, 2001). Another type of triangulation is methodology triangulation, which means use of more than two methods for the investigation of same phenomenon. (Ellen Sullivan, 1986) This kind of triangulation may occur at different levels of research, such as, data collection or data analysis and is frequently used in social science researches (Shih, 2001)(Shih, 2001). The researcher has proposed a new model that can be used for the analysis of political text by those researcher who are interested in digital discourse.

\section{Results and Discussion}

Socio-cognitive model of Van Dijk also appeared as supporting theoretical foundation, the researcher suggest that it can be taken it as a theory or as a method. The micro-macro level categories of analysis point towards the important element of discourse analysis i.e., how linguistic elements along with contextual practices facilitate to unpack the strategies and means used in (re)construction and (re)presentation of identity. Within similar context the researcher has relied upon the theoretical underpinning of socio-cognitive model to achieve the research 
objectives. "Ideological square" remained central to theoretical and methodological perspective of the current study, as it highlights the notion of "positive-representation of us and negative -representation of others".

While discussing about the social and political identity theory, the researcher has focused upon the core elements that states "individuals and groups affiliate themselves with certain groups and thus create their political identities accordingly". Moreover, when individuals/groups affiliate themselves with certain political groups on the basis of certain shared values and attitudes then they start believing on the ideologies of those groups and they simply "own" them. Similar phenomenon is central to the objectives and analysis of the current study. The political identity (re)construction and (re)presentation is crucial for the current study, from theoretical perspective.

Clusivity theory is one of the significant theory that is exclusively applied on the political texts to highlight the "inclusive and exclusive" categories of representation. In the current study the proposed model can help to find out how inclusion and exclusions are done at inter- group level and at intra-group level.

Since the data can be taken from social media i.e., twitter, so it is also essential to take the theoretical perspective of social media theory into account. Social media discourse have four affordances that makes it unique from other types of discourses i.e., it is persistent, replicable, scalable and searchable. As the discourse taken from twitter requires its users to say/convey their messages within 140 characters, so this discourse appears interesting, short and crisp. Political discourse, which is taken from social media is termed valid by the researcher due to above mentioned four features. This specific political discourse can be archived and it is real time; discourse, secondly it has broad visibility and it allows users to get and provide a quick access to their desired topics and contents. This very nature/property of twitter discourse enables researcher to validate the certain ideological stances of political actors in different time periods with exact dates etc.

Triangulation of theory can be deliberated in the current scholarship because the researcher believed that triangulation strengthen the answers to research queries and thus facilitates validity of results from analytical perspective.

As the model developed by the researcher has many unique features so it can be easily applied on political text that are taken from any social media sites and thus these texts can be analysed for multiple objectives such as to identity the identities of the discourse makers, to find out their alliances etc.

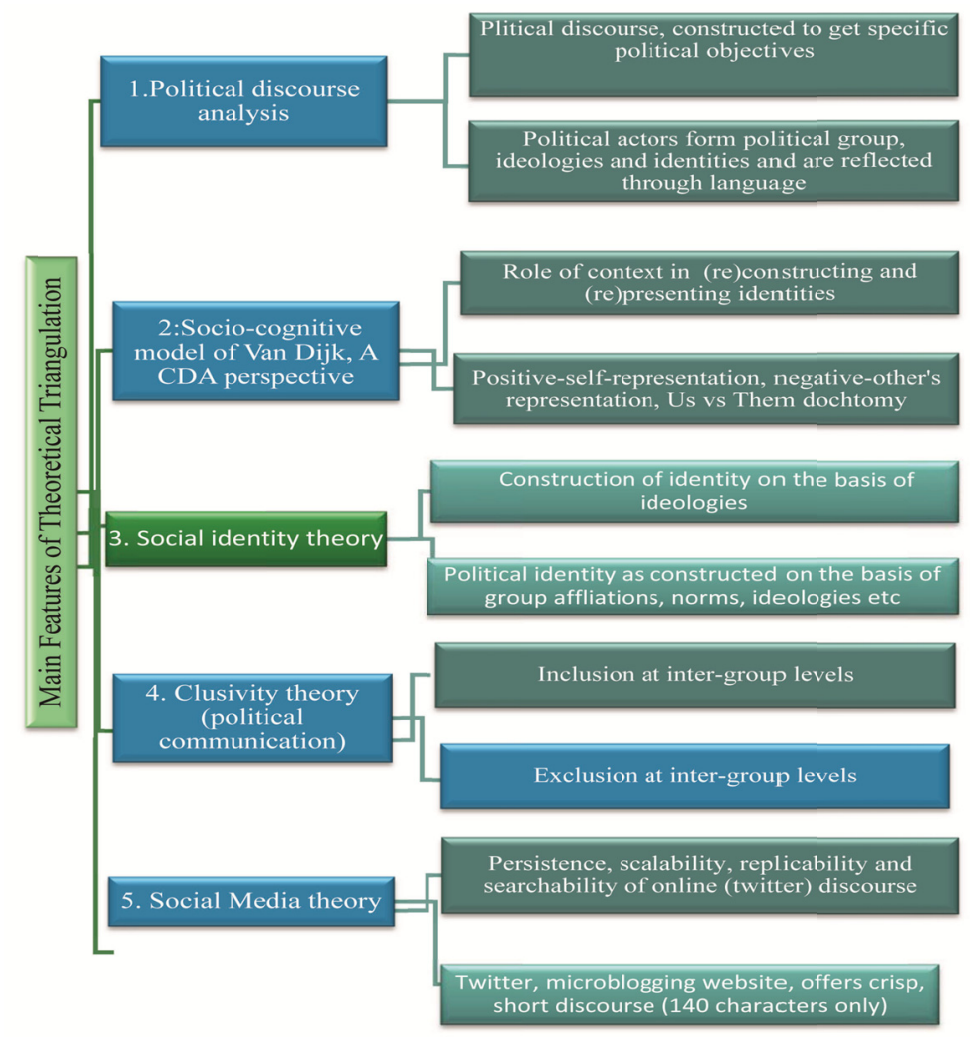

Figure 3. Proposed model for the analysis of social media political discourse 
This model is developed by the researcher after the study of all above mentioned theories and finally these key constructs were taken into account to make this model comprehensive and effective for the future researchers. So it can be stated by the researcher that the above mentioned theoretical model will facilitate the researchers who are interested in analysis of digital political discourse and this model will also offer multiple lenses to the researchers.

\section{References}

Abrams, D. (2006). Political distinctiveness: An identity optimising approach. European Journal of Social Psychology, 24(3), 357-365. https://doi.org/10.1002/ejsp.2420240305

Abrams, D., Hogg, M., \& Marques, J. (2004). Social Psychology of Inclusion and Exclusion. London: Psychology Press.

Begley, C. M. (1996). Triangulation of communication skills in qualitative research instruments. Journal of Advanced Nursing, 24(4), 688-693. https://doi.org/10.1046/j.1365-2648.1996.02446.x

Cap, P. (2006). Legitimisation in Political Discourse: A Cross-Disciplinary Perspective on the Modern US War Rhetoric. Cambridge: Cambridge Scholar publishers.

Chilton, P. (2004). Analysing Political Discourse: Theory and Practice. London, New York: Routledge.

Chilton, P., \& Schäffner, C. (Eds.). (2002). Discourse Approaches to Politics, Society and Culture (Vol. 4). Amsterdam Philadelphi: John Benjamins Publishing Company. https://doi.org/10.1075/dapsac.4

Duck, J. M., Hogg, M. A., \& Terry, D. J. (1995). Me, us and them: Political identification and the third-person effect in the 1993 Australian federal election. European Journal of Social Psychology, 25, 192-215. https://doi.org/10.1002/ejsp.2420250206

Ellen Sullivan, M. (1986). Multiple triangulation: a methodology for nursing science. Advances in Nursing Science.

Esses, V. M., Dovidio, J. F., Jackson, L. M., \& Armstrong, T. L. (2011). The immigration dilemma.The role of perceived group competition, ethnic prejudice, and national identity. Journal of Social Issues, 57, 389-412. https://doi.org/10.1111/0022-4537.00220

Johnson, D. W., \& Johnson, R. T. (2000). Civil Political Discourse in a Democracy: The Contribution of Psychology. Peace and Conflict: Journal of Peace Psychology, 6(4), 291-317. https://doi.org/10.1207/S15327949PAC0604_01

Meister, D. (2001). Practice what you preach. New York: Free Press.

Sekaran, U., \& Bougie, R. (2010). Research Methods for Business: A Skill Building Approach. New York: John Wiley \& Sons.

Sheyholislami, J. (2001). Yesterday's "separatists" are today's "resistance fighters". In A Critical Discourse Analysis of the representation of Iraqi Kurds in The Globe and Mail and The New York Times. Unpublished Mater's Thesis Ottowa, Canada: Carleton University. Retrieved from http//server.carleton.ca/ jsheyhol/articles/what\%20is\%20CDA.pdf

Shih, F. J. (2001). Triangulation in nursing research: issues of conceptual clarity and purpose. Journal of Advancing Nursing, 28(3), 631-641. https://doi.org/10.1046/j.1365-2648.1998.00716.x

Van Dijk, T. (1998c). What is Political Discourse Analysis? In J. Blommaert \& C. Bbulcae (Eds.), Discourse and society (pp. 11-52).

Wieczorek, A. E. (2013). Clusivity: A New Approach to Association and Dissociation in Political Discourse. Newcastle: Cambridge Scholars Publishing.

Wodak, R. (2009). The Discourse of Politics in Action Politics as Usual. New York: PALGRAVE MACMILLAN.

Wodak, R., \& Meyer, M. (2001). METHODS OF CRITICAL DISCOURSE ANALYSIS . London, Thousand Oaks, New Delhi: Sage publications. https://doi.org/10.4135/9780857028020

\section{Copyrights}

Copyright for this article is retained by the author(s), with first publication rights granted to the journal.

This is an open-access article distributed under the terms and conditions of the Creative Commons Attribution license (http://creativecommons.org/licenses/by/4.0/). 